\title{
ARID1A Positive
}

National Cancer Institute

\section{Source}

National Cancer Institute. ARID1A Positive. NCI Thesaurus. Code C154954.

An indication that ARID1A expression has been detected in a sample. 